\title{
HEALTH PROBLEMS AND ACCESS TO HEALTH CARE SERVICES FOR THE PERSONS WITH DISABILITIES IN LAHORE.
}

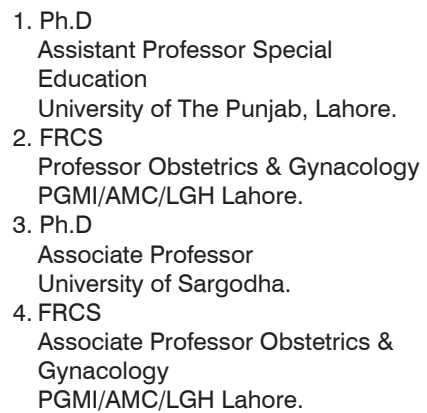

Correspondence Address: Dr. Samina Ashraf

Department of Special Education University of the Punjab, Lahore. miss_saminadse@yahoo.com

Article received on:

11/04/2020

Accepted for publication: $27 / 06 / 2020$

\begin{abstract}
Samina Ashraf', Maimonna Ashraf ${ }^{2}$, Uzair-ul-Hassan ${ }^{3}$, Naila Yasmeen ${ }^{4}$
ABSTRACT... Objectives: This study aims to explore the major health problems of persons with disabilities, to see the difference between the health problems of persons with mild to moderate and severe to profound disabilities, and highlight the problems. Study Design: Quantitative Study. Setting: University of the Punjab, Lahore. Period: 09 months from 15 March 2018 to 14 Dec 2018. Material \& Methods: The study included a quantitative survey conducted with interviews of 100 persons with different disabilities ( 50 mild to moderate disabilities, 50 severe to profound disabilities) selected by applying convenient sampling method. A questionnaire was used for the data collection. The questionnainaire comprised of three parts: first part was about demographics,the second part consisted of items related to the health problems and third part consisted of items related to the access to health care services. Non-parametric statistical analysis was used for the data analysis. Comparison between persons with mild to moderate and severe to profound disabilities was made. Results: Results showed that persons with severe to profound disabilities generally experienced more health problems and problems in accessing health care services as compared to persons with mild to moderate disabilities. Conclusion: The study concluded that persons with disabilities experience physical, attitudinal and communication problems while accessing health services.
\end{abstract}

Key words: $\quad$ Access, Health Problems, Health Care, Mild Disabilities, Severe Disabilities.

Article Citation: Ashraf S, Ashraf M, Uzair-ul-Hassan, Yasmeee N. Health Problems and access to health care services for the persons with disabilities in Lahore. Professional Med J 2020; 27(10):2241-2246.

DOI: $10.29309 / T P M J / 2020.27 .10 .4630$

\section{INTRODUCTION}

Disability is an umbrella term that includes impairments, limitations, and restrictions as described by the WHO as a part of international classification system. ${ }^{1}$ People with disabilities are classified into four major majorcategories i.e., hearing impairment, visual impairment, physical disabilities and intellectual disabilities. ${ }^{2}$ Health is major aspect of our life. The World Health Organization defines health as "a complete state of physical, mental and social well-being, and not merely the absence of disease or infirmity. ${ }^{1,3}$

In Pakistan provision of health care services is responsibility of the government. Today, the doctor patient population ratio stands at 1: 997, dentist 1: 10658 and hospital bed 1:1584. While national health infrastructure comprises of 1201 hospitals, Basic health units 5518, Rural Health Centers 683, Dispensaries 5802, Maternity \&
Child Health Centers 731 and TB centers 347, and the total availability of beds in these health facilities is estimated at 123394 . To provide health facilities to general population government has been spending 0.5 to $0.8 \%$ of its GDP over the last ten years. In fiscal year 2017-18 a separate amount of 384.54 billion has allocatedto the health department. ${ }^{4}$ Sofar, separate quota has not been allocated for persons with disabilities though they account for $10 \%$ (WHO, 1998) of our population. Whereas, globallyover a bllion, (15 percent) of the world's population is with some type of disability. ${ }^{5}$

People with disabilities have the greater general health care needs then everyone else, including the need of access to mainstream health care services.Disability does not accompany always with some health problem. However, persons with disabilities are at a greater risk of getting 
health problems due to their certain physical and psychological conditions. ${ }^{6}$ The number of persons living with disabilities is growing as a result of factors such as population increase, ageing, and medical advances that preserve and prolong life. Hence, persons with disabilities may have greater health needs than the general population(Inclusive health services report, 2018). There are certain disabilities which are associated with certain health conditions most prominently in case of intellectual disability, muskoskeletal problems andcerebral palsy.Article 25 of the UN Convention on the Rights of Persons with Disabilities (UNCRPD) reinforces the right of persons with disabilities to attain the highest standard of health care, without discrimination. ${ }^{7}$ This study explores the major health problems of persons with major and minor disabilities and nature of problems they experience in accessing the health services in our social context.

The study will have impact on the quality of health care of persons with disabilities by highlighting the problems they are facing in accseeing health facilities in their locality. The study will sensitize the society towards the health needs of the persons with mild, severe and profound disabilities and hence the awareness will raised in the local communities and among policy makers. The study will add in the body of knowlde regarding persons with disabilities health problems and facilities available to address these problems.

1. To identify the major health problems of persons with disabilities.

2. To explore the problems faced by the persons with disabilities in accessing health care services.

3. To see the difference between the health problems of persons with mild to moderate and severe to profound disabilities.

4. To highlight the general health care services provided by the Government to the persons with disabilities.

\section{MATERIALS AND METHODS}

Present study was conducted on health problems and access to health care services by the persons with disabilities. Researchers used descriptive research design to conduct the study.

A survey was conducted to collect the data. A questionnaire was developed to collect the data. The questionnaire was comprised of three parts: first part was related to demographics, 2nd was related with major health problems fac ed by the persons with disabilities and third part was related with the access to health care services. The respondents were provided two options to respond i.e., Yes, No against each item. The reliability of the questionnaire was (.81) estimated with the help of cronbach alpha formula. The targeted population of the study consisted of persons with disabilities living in the urban areas of Lahore visiting public sector hospital in their vicinity from the age group of 20 to 45 . A total number of 100 persons with different disabilities (50 with mild to moderate, 50 with severe to profound) who has or had the certain health problems in the period of last two years of their life and had consulted Government sector hospital during their period of illness were taken as sample of the study. The study duration was 09 months from 15 March 2018 to 14 Dec 2018. Only those persons were taken as sample who were conveniently available for the researchers and willing to be part of the study. The researchers personally met with every respondent and fill up the questionnaires. In case of persons with hearing impairment, the researchers used sign language to explain the questions and for blind persons researchers read out loudly the questionnaires for them. Collected data were subjected to quantitative analysis by using SPSS. Frequency of the responses alongwith their percentages was calculated and Mann-Whitney test was performed to see the difference between the health problems of persons with mild and severe disabilities.

\section{RESULTS}

The above table shows the sample characteristics. $50 \%$ of the sample was with mild to moderateand $50 \%$ was with severe to profound disabilities. Whereas $53 \%$ of the sample was male and $47 \%$ was female.

The above table shows that the prevalence of 
headache, hypertension, anemia, anxiety and muscle problems, diabetes, depression, upper respiratory tract infection are common health problems of persons with disabilities.

The above table shows that according to majority of the persons with disabilities, the facility of hospital services is available for them in hospitals catering general population. No separate purpose build area for them in hoapital vicinity, onlyramps are available in the hospitals and the buildings are not completely barriers free. The major health services which the government is providing are emergency facility, out - door facility, ambulance, diagnostic testing and treatment, food for hospitalized patients and accommodation facility.

They are also facing problems with the attitude of para medical staff. The respondents also mentioned that majority of the nursing staff have only primary level of knowledge of disability. A good number of respondents said that the psychological environment of the hospitals is not good. More than half of the respondents responded that they also faced communication problems while dealing with medical staff in the hospital. Moreover, all of the persons with disabilities are notbeing provided with the facility of health insurance.

\begin{tabular}{|c|l|c|c|c|}
\hline Sr. No & & & Frequency & $\%$ \\
\hline \multirow{2}{*}{1} & \multirow{2}{*}{ Gender } & Male & 53 & 53 \\
\hline \multirow{2}{*}{3} & \multirow{2}{*}{ Profession } & Female & 47 & 47 \\
\hline \multirow{2}{*}{5} & \multirow{2}{*}{ Category of Impairment } & Professional & 59 & 59 \\
\cline { 2 - 4 } & & Student & 41 & 51 \\
\cline { 2 - 4 } & & Mild to moderate & 50 & 50 \\
\hline
\end{tabular}

Table-I. Summary Table of demographics of the respondents.

\begin{tabular}{|l|l|c|c|}
\hline $\begin{array}{c}\text { Sr. } \\
\text { No. }\end{array}$ & \multicolumn{1}{|c|}{ Name of Health Problem } & $\begin{array}{c}\text { Persons with Severe to Profound } \\
\text { Disabilities } \mathbf{N}=\mathbf{5 0}\end{array}$ & $\begin{array}{c}\text { Persons With Mild to Moderate } \\
\text { Disabilities } \mathbf{N}=\mathbf{5 0}\end{array}$ \\
\hline & Anemia & 45 & 30 \\
\hline & Headache & 45 & 30 \\
\hline Anxiety & 34 & 15 \\
\hline Diabetes & 13 & 5 \\
\hline Muscoskeletal problems problems & & 10 \\
\hline Vitamin deficiency & 12 & 10 \\
\hline Hypertension & 12 & Nil \\
\hline Asthma & 09 & Nil \\
\hline Fatigue & 10 & Nil \\
\hline Depression & 07 & 10 \\
\hline Headache & 15 & 03 \\
\hline Upper respiratory tract infections & 07 & 01 \\
\hline Obesity & 05 & 03 \\
\hline Hepatitis & 05 & 05 \\
\hline Thyroid Problem & 05 & Nil \\
\hline Tuberculosis & Nil & Nil \\
\hline Seizures & Nil & 5 \\
\hline
\end{tabular}

Table-II. Prevalence of health problems in persons with mild to moderate and severeto profound disabilities. 


\begin{tabular}{|c|c|c|c|}
\hline Sr. & Questions & Yes $\%$ & No $\%$ \\
\hline 1 & Is facility of hospital available to you? & 62 & 38 \\
\hline 2 & Are ramps available at the entry of the hospital building? & 83 & 17 \\
\hline 3 & Are the ramps available in the entire building of hospital? & 75 & 25 \\
\hline 4 & Is the lift facility available in the hospital? & 65 & 35 \\
\hline 5 & Is the building of hospital barrier free? & 26 & 74 \\
\hline 6 & Is the hospital parking have enough space for parking vehicles? & 61 & 39 \\
\hline 7 & Do the hospital administrations provide you accommodation? & 64 & 36 \\
\hline 8 & Is the physical environment of hospital good? & 25 & 75 \\
\hline 9 & Is the psychological environment of hospital good? & 38 & 62 \\
\hline 10 & Is the attitude of hospital administration positive towards you? & 45 & 55 \\
\hline 11 & Is the mechanism of getting health facilities is difficult for the patient? & 68 & 32 \\
\hline 12 & Does the hospital entertain you in emergency? & 78 & 22 \\
\hline 13 & Do the emergency staff understand your problem easily? & 32 & 68 \\
\hline 14 & Is the emergency facility provided free of cost? & 53 & 47 \\
\hline 15 & Are the doctors always available to you? & 52 & 48 \\
\hline 16 & Do the doctors have knowledge of disability? & 85 & 15 \\
\hline 17 & Do the paramedical staff have knowledge of disability? & 82 & 18 \\
\hline 18 & Do you face difficulty in scheduling appointment from physicians? & 62 & 38 \\
\hline 19 & Does the specialist doctors give you proper time? & 72 & 28 \\
\hline 20 & Does the physician deal you with respect? & 55 & 45 \\
\hline 21 & Do the overall attitude of physiciansis empathetic with you? & 49 & 51 \\
\hline 22 & Does the Para-medical staff deal you with respect and patience? & 63 & 37 \\
\hline 23 & Does the Para-medical staff show personal concern to provide to relief? & 41 & 59 \\
\hline 24 & Does the Para-medical staff understand your communication? & 34 & 66 \\
\hline 25 & Are all the medicines available in market near to hospital or your home? & 34 & 66 \\
\hline 26 & Is every type of medicine in your purchaise power? & 27 & 73 \\
\hline 27 & Are the medicines available in market same as prescribed by the doctors? & 85 & 15 \\
\hline 28 & Is the medical facility costly for you? & 61 & 39 \\
\hline 29 & Is the public transport facility available to visit the hospital? & 61 & 39 \\
\hline 30 & Do the counciling facility is available for you in hospital & 0 & 100 \\
\hline 31 & Are you being provided with the services of health insurance by Government? & 0 & 100 \\
\hline
\end{tabular}

Table-III. Frequency of the responses on access of health care services obtained from persons with disabilities (PWDs.

\begin{tabular}{|l|c|c|c|c|}
\hline \multicolumn{1}{|c|}{ Type of Disability } & N & Mean Rank & Mann-Whitney Z & \\
\hline Mild to moderate disabilities & 50 & 39.92 & Z & -3.573 \\
\hline Severe to profound Disabilities & 50 & 60.08 & Sig & .000 \\
\hline Total & 100 & & & \\
\hline
\end{tabular}

Table-IV. Mann-Whitney test was performed to compare the prevelance ofhealth problems between persons with minor and major disabilities.

The above table shows that persons with severe to profound disabilities are facing more problems in accessing health facilities as compared to persons with mild to moderate disabilities(Mean Mild to moderate disabilities $=39.92$, and Mean of severe to profound disabilities $=60.08, \mathrm{Sig}=.000$ ) .

\section{DISCUSSION}

Disability is an evolving field within public health in Pakistan. People with disabilities account for more than $10 \%$ of the Pakistan population, but most of their health needs remain unmet due to less access to health facilities..$^{1,8}$ The persons with severe to profound disabilities are suffering with the same health problems which the persons with mild to moderate disabilitiesare suffering but prevalence and magnitude of health problems are higher among persons with severe to profound 
disabilities as shown in our study .These findings are inline with the study conducted by Karahn, Walker \&Correa(2015). ${ }^{9}$ Another finding of the study showing that the various types of health impairments such as muscoskeletal problems, anemia, obesity and fatigue, menstrual problems (only in females) ${ }^{10}$, seizure disorders and depression are more common in persons with major disabilities is in conformity with the some of international research studies. ${ }^{11,12,13}$

The major health care services available for persons with disabilities in the Government hospitals of Lahore are qualified Doctors, nurses, para-medicsand hospitals but they are insufficient to meet health needs of persons with disabilities. ${ }^{14}$ This research also showed that major barriers to get health services are accessibility, physical, communication and attitudinal barriers. The study conducted by Daras, Konstantinos, et al(2018) has same findings. ${ }^{15}$ According Iftikhar, Alamgir, Maqbool, Rehan \& Akhtar (2019) healthcare providers hold poor knowledge and, often incorrect, notions about persons with disabilities. ${ }^{16,17}$ Due to incorrect presumptions, healthcare providers have been shown not to communicate clearly with PWDs regarding their disease and its prevention. ${ }^{18,19,20,21,22}$ Our study has highlighted non-existence of health insurance policy for persons with disabilities while it is in practice in developed and some underdeveloped countries. ${ }^{19}$ Thus our study has drawn attention of health policy makers to look into this ever increasing need of healthcare services for the persons with dsabilities.

\section{CONCLUSION}

Our study concludes that persons wih disabilities are suffering from lot of health problems and difficulties in access to health care services which is further compounded by physical,attitudinal and communication factors. Thus highlighting urgent need to mprove all areas of health care for patients with disabilities in the future health programs of the government. The physical infrastructure need to be barrier free and both medical and para-medical staff should be trained to use alternative modes of communication for the better understanding of the health problems of persons with disabilities e.g., sign language, picture exchange communication systems etc. Moreover, the rehabilitation professionals should extend their services into community based fitness centers too. Finaly, health insurance services should be offered to all persons with disabilitie.

Copyright $(27$ June, 2020.

\section{REFERENCES}

1. World Health Organization: Disability and health. 2018. Retrieved on July 2018 from http://www.who.int/ news-room/fact-sheets/detail/disability-and-health.

2. Kirk S, Gallagher JJ, Coleman MR, Anastasiow NJ. Educating exceptional children. Cengage Learning; 2011.

3. Svalastog AL, Donev D, Jahren Kristoffersen N, Gajović $S$. Concepts and definitions of health and healthrelated values in the knowledge landscapes of the digital society. Croat Med J. 2017; 58 (6):431-435. doi:10.3325/cmj.2017.58.431.

4. Pakistan Economic survey year (2017-18). Available on www. finance.gov.pk.

5. Hafiz-ur-Rahman M. Singh A. Socio-economic disparity in the occurrence of disability among older adults in six low and middle income countries, Int $\mathrm{J}$ Health Hum Rights in Health Care. 2019; 12(1):60-75.

6. Okoro CA, Hollis ND, Cyrus AC, Griffin-Blake S. Prevalence of disabilities and health care access by disability status and type among adults-United States, 2016. Morbidity and Mortality Weekly Report. 2018 Aug 17;67(32):882.

7. Hoffman SJ, Sritharan L, Tejpar A. Is the UN Convention on the Rights of Persons with Disabilities impacting mental health laws and policies in high-income countries? A case study of implementation in Canada. BMC international health and human rights. 2016 Dec 1;16(1):28. doi:10.1186/s12914-016-0103-1.

8. Kumar S, Bano S, Comparison and analysis of health care delivery systems: Pakistan versus Bangladesh. J Hosp Med Manage. 2017, 3(1):21-22.

9. Krahn GL, Walker DK, Correa-De-Araujo R. Persons with disabilities as an unrecognized health disparity population. Am J Public Health. 2015; 105(2):198-206. http://doi.org/10.2105/AJPH.2014.302182.7. 
10. Nurkhairulnisa Al, ChewKT, Zainudin AA, et al. Management of menstrual disorder in adolescent girls with intellectual disabilities: A blessing or a curse? Obstet Gynecol Int. 2018;3:50-54. doi:10.1155/2018/979568.

11. Friedrich $M$. Depression is the leading cause of disability around the world. JAMA. 2017;317(15):1517. doi:10.1001/jama.2017.3826.

12. Moradi F, Sarabandi A, Soltani S. Obesity in people with disability: The implications for health care expenditures. J Res Med Sci. 2016; 21 (26):80-84.

13. Obi SO. Interventions for Students with Physical Disabilities and Other Health Impairments. Viewpoints on Interventions for Learners with Disabilities. 2018 May 18;33:197-220.

14. Pakistan demographic and health survey report (2017-18) Prepared by national institute of population studies Islamabad, Pakistan. (August,2018).

15. Daras K, Davies A, Green M, Singleton A. Developing indicators for measuring health-related features of neighbourhoods. Consumer data research. $2018 \mathrm{Apr}$ 30:167-77. JSTOR, www.jstor.org/stable/j.ctvqhsn6.15.

16. Iftikhar K, Alamgir A, Maqbool S, Rehan W, Akhtar S. Knowledge and attitude of health care professionals towards persons with disabilities. Pak Armed Force Medical J. 2019; 69 (1):147-153.
17. Devkota HR, Murray E, Kett M,Groce N. Healthcare provider's attitude towards disability and experience of women with disabilities in the use of maternal healthcare service in rural Nepal, Reprod Health. 2017; 14(1):79.

18. Elena S. Rotarou \& Dikaios $S$. Inequalities in access to health care for people with disabilities in Chile: The limits of universal health coverage. Critical Public Health, 2017; 27:5, 604616, DOI:10.1080/09581596.2016.1275524.

19. Sakellariou D, Rotarou ES. Access to healthcare for men and women with disabilities in the UK: Secondary analysis of cross-sectional data BMJ Open 2017; 7 : e016614. doi: 10.1136/bmjopen-2017-016614.

20. Badu, Eric, Maxwell P. Opoku Seth CY. Appiah. Attitudes of health service providers: The perspective of persons with disabilities in the kumasi metropolis of Ghana. African Journal of Disability [Online].2016; 5(1).

21. Nancy S, Katharine M, Mauora DI. Decreasing health disparities for people with disabilities through improved communication strategies and awareness. International journal of environment and public health. 2015;12(3):3301-3316. doi:10.3390/ijerph120303301.

22. Ruger JP, Mitra S. Health disability and capability approach; In Mitra S, Ruger JP (Ed.) Health disability and capability approach an introduction. Routledge Publishers. 2019; 1-11.

\section{AUTHORSHIP AND CONTRIBUTION DECLARATION}

\begin{tabular}{|c|l|l|l|}
\hline Sr. \# & Author(s) Full Name & \multicolumn{1}{|c|}{ Contribution to the paper } \\
\hline 1 & Samina Ashraf & $\begin{array}{l}\text { Principal author, conceive the main } \\
\text { idea, develop instrument, Data } \\
\text { collected, Data analysis. } \\
\text { Data collection, Literature review. }\end{array}$ \\
\hline 2 & Maimonna Ashraf & $\begin{array}{l}\text { Final review of paper, proof } \\
\text { reading. }\end{array}$ \\
\hline 4 & Uzair-ul-Hassan & Naila Yasmeen & Final review of paper and editing. \\
\hline
\end{tabular}

